\title{
Agenda 2030 e Energias Renováveis: sinergias e desafios para alcance do desenvolvimento sustentável
}

\author{
2030 Agenda and Renewable Energy: synergies and challenges to achieve sustainable development \\ Agenda 2030 y Energias Renovables: sinergias y desafíos para lograr el desarrollo sostenible
}

Recebido: 30/11/2021 | Revisado: 05/12/2021 | Aceito: 11/12/2021 | Publicado: 20/12/2021

Marta Emília Aires Cavalcante de Farias
ORCID: https://orcid.org/0000-0002-3515-0143
Universidade Federal de Campina Grande, Brasil
E-mail: marta_aaires@ hotmail.com
Maria de Fátima Martins
ORCID: https://orcid.org/0000-0002-9578-9555
Universidade Federal de Campina Grande, Brasil
E-mail: fatima.martins@ @ufcg.edu.br
Gesinaldo Ataíde Cândido
ORCID: http://orcid.org/0000-0002-3112-0254
Universidade Federal de Campina Grande, Brasil
E-mail: gacandido@ uol.com.br

\begin{abstract}
Resumo
O setor energético em nível global se configura como uma das pautas mais discutida no atual século, cuja centralização do debate permeia em torno da emergência de se estabelecer novos padrões de produção e consumo numa perspectiva de sustentabilidade. Nesse sentido, a legitimação e importância do tema foi reconhecida em 2015 pela Organização das Nações Unidas (ONU) na ocasião do lançamento da Agenda 2030. Dessa conjuntura, a partir de uma abordagem multidisciplinar e integrada, tratando do contexto das energias renováveis, especialmente fonte eólica, consta como objeto central do presente estudo analisar a luz da Agenda 2030 e seus respectivos objetivos quais possíveis sinergias e desafios. Para este fim, o percurso metodológico seguiu os caminhos da pesquisa exploratória e descritiva com instrumento de coleta de dados através de pesquisa bibliográfica e documental. Os resultados obtidos evidenciam sinergias entre o setor eólico e os ODS. Do lado dos desafios, foram evidenciados ausência de alinhamento entre políticas públicas e ODS numa perspectiva de integração para alcance da sustentabilidade energética.
\end{abstract}

Palavras-chave: Setor energético; Agenda 2030; ODS; Sinergias; Políticas públicas.

\begin{abstract}
The energy sector at a global level is one of the most discussed agendas in the current century, whose centralization of the debate permeates the emergence of establishing new patterns of production and consumption in a perspective of sustainability. In this sense, the legitimacy and importance of the topic was recognized in 2015 by the United Nations (UN) on the occasion of the launch of the 2030 agenda. From this juncture, from a multidisciplinary and integrated approach, dealing with the context of renewable energies, especially wind, the main object of this study is to analyze the light of the 2030 agenda and its respective objectives, which are possible synergies and challenges. To this end, the methodological path followed the ways of exploratory and descriptive research with a data collection instrument through bibliographical and documentary research. The results obtained show synergies between the wind sector and the SDGs. On the challenges side, the lack of alignment between public policies and SDGs in a perspective of integration to achieve energy sustainability was evidenced.
\end{abstract}

Keywords: Energy sector; 2030 Agenda; ODS; Synergies; Public policy.

\section{Resumen}

El sector energético a nivel global se configura como una de las pautas más discutidas en el actual siglo, cuya centralización del debate impregna en torno a la emergencia de establecer nuevos modelos de producción y consumo desde una perspectiva de sostenibilidad. En este sentido, la legitimación e importancia del tema fue reconocida en 2015 por la Organización de las Naciones Unidas (ONU) con motivo del lanzamiento de la Agenda 2030. De esta coyuntura, a partir de un enfoque multidisciplinar e integrado, en el contexto de las energías renovables, especialmente fuente eólica, consta como objeto central del presente estudio analizar la luz de la Agenda 2030 y sus respectivos objetivos como posibles sinergias y desafíos. Para este fin, el camino metodológico siguió los caminos de la investigación exploratoria y descriptiva con instrumento de recolección de datos a través de investigación bibliográfica y documental. Los resultados obtenidos muestran sinergias entre el sector eólico y los ODS. Por el lado 
de los desafíos, se puso de manifiesto la falta de alineamiento entre políticas públicas y ODS en una perspectiva de integración para alcanzar la sostenibilidad energética.

Palabras clave: Sector energético; Agenda 2030; ODS; Sinergias; Políticas públicas.

\section{Introdução}

As Organizações das Nações Unidas (ONU) em 2015 institui a Agenda 2030, "Transformando nosso mundo" denominada de Objetivos de Desenvolvimento Sustentável (ODS) composta de 17 objetivos e 169 metas, tratando de uma diversidade de temas estabelecidos em acordo com demandas da sociedade contemporânea e como também questões secularmente reconhecidas como combate à pobreza e valoração da justiça social. Em aspectos gerais, a agenda consta de um plano de ação cujo pilar de sustentação se estabelece sob cinco eixos: erradicar a pobreza; proteger o planeta; garantir que as pessoas alcancem paz e prosperidade e transformar o mundo (Pessoa et al. 2019).

Tratando especialmente do eixo que se direciona para proteção do planeta, se apresenta como estratégico pensar as questões relacionadas a produção de energia, visto que, tem ocupado espaço relevante no cenário das discussões sobre meio ambiente e na construção de modelo sustentável de desenvolvimento e sustentabilidade (Philippi et al. 2016). Tal abertura, advêm tanto pela crescente demanda, como pelos impactos negativos atribuídos ao uso dos combustíveis fósseis, aumento dos gases de efeito estufa (GEE) e os complexos desafios ambientais relacionados as mudanças climáticas. Logo, seguindo tendências dos acordos e tratados internacionais a exemplo do Protocolo de Quioto e mais recentemente o Acordo de Paris, que trataram da emergência de se estabelecer novos padrões e consumo de energia pautado no modelo sustentável, os caminhos que passam a condicionar o setor energético mundial assume especial importância as fontes alternativas de energia, ou fontes modernas onde se encaixam as energias renováveis, como solar, eólica, geotérmica, hidrelétrica, biomassa que são utilizadas para geração de eletricidade.

No movimento que se segue acerca do novo paradigma energético sustentável, a Organização das Nações Unidas (ONU) reconhece a importância e emergência do tema ao dispor dentre os seus dezessete objetivos, dois diretamente voltados para questão energética. Sendo o de número 7 (sete), e 13 (treze), nos quais estabelecem respectivamente metas para o setor energético em bases sustentáveis. O objetivo 7 (sete) trata de assegurar o acesso confiável, sustentável, moderno e a preço acessível à energia para todos. O correspondente ao objetivo 13 (treze) se refere a adoção de medidas urgentes para o combate as mudanças climáticas e seus impactos (Ipea, 2018).

As energias renováveis se consolidam, sob a égide de energia limpa por contribuírem com diversificação da matriz energética e serem menos impactantes. As fontes renováveis para geração de energia elétrica devem estar alinhadas à ideia do desenvolvimento sustentável (Borges et al. 2015). O desenvolvimento sustentável requer uma matriz energética apropriada, limpa, econômica e sobretudo orientada pela perspectiva de um desenvolvimento para todos (Acselrad et al. 1999). Em termos de matriz energética, o Brasil, em relação à média mundial ocupa lugar de destaque. Conforme o Balanço Energético Nacional (Ben, 2020) o país dispõe de uma matriz elétrica de origem predominantemente renovável, com destaque para a fonte hídrica que responde por $64,9 \%$ da oferta interna. Destaca-se nesse contexto a crescente expansão da fonte eólica que conforme atestam os dados do sistema de geração da ANEEL (SIGA) a capacidade instalada nacional corresponde a 15,5 (GW) o que equivale a 9\% da matriz de energia elétrica, condição que coloca o país no patamar de liderança na América Latina e oitavo maior do mundo (Gwec, 2019).

Cumpre destacar que, a condição de uma matriz energética baseada em fontes modernas e renováveis não se encerra como requisito para alcance do desenvolvimento que seja sustentável. Visto que, a produção de energia em qualquer modalidade está fortemente caracterizada como uma das atividades mais intensivas na exploração dos recursos naturais e impactos socioambientais, portanto, cercada de desafios relacionados ao alcance do desenvolvimento sustentável. Acresce ainda que o contexto a que se refere a produção e oferta de energia se apresenta circundado por uma complexa rede de fatos e 
fatores que se entrelaçam. Por consequência, se revela como um vasto campo de debates situado a partir da interação simultânea entre energia, sociedade, natureza, equidade, desenvolvimento e sustentabilidade. Nesse sentido, torna-se salutar pensar o tema a partir de uma abordagem ampla, multidisciplinar, holística e integrada desvinculando-se de um debate meramente técnico e econômico, visão comumente associada ao tema. Reitera que as mudanças em curso no setor energético mundial se caminham para exigência de novas configurações nas quais, se incluem a construção de políticas públicas convergentes com princípios de equidade e justiça social.

Desse contexto, coloca-se para questão de análise nesse estudo identificar as oportunidades de integração entre os ODS e políticas públicas para o setor de energia eólica. De modo complementar, consta como objeto central do presente estudo analisar a luz da Agenda 2030 e seus respectivos objetivos quais possíveis sinergias e desafios para o setor. As respostas para tais questões perpassam pela necessidade de uma abordagem sistêmica e integrada dos instrumentos que regem políticas públicas, energias renováveis e Agenda 2030.

O percurso metodológico seguiu os caminhos da pesquisa exploratória e descritiva com instrumento de coleta de dados por meio de pesquisa bibliográfica e documental. A proposição da presente pesquisa assume importância ao passo que pode fornecer importantes contribuições para subsidiar o preenchimento de lacunas que visem obter respostas para estudos acerca das políticas públicas, energia renovável e ODS e desse modo direcionar possíveis ajustes no modelo de políticas direcionadas ao setor eólico no Brasil. Quanto a sua estrutura, além da introdução, o texto encontra-se organizado em tópicos, o primeiro consta da fundamentação teórica onde apresenta a relação entre a Agenda 2030 e o setor energético, o segundo discorre sobre o lugar da energia no contexto do desenvolvimento relacionando com políticas públicas. Na sequência descreve o percurso metodológico, análise dos resultados e por fim, discussões e conclusões.

\section{Referencial teórico}

\subsection{A Agenda 2030, Objetivos do Desenvolvimento Sustentável e setor energético: perspectivas de sinergias}

$\mathrm{O}$ aporte em energia assume importância crescente, seja pelas demandas do mundo moderno, como por sua interdependência com questões de segurança energética, melhoria das condições de vida, crescimento econômico e sustentabilidade ambiental. Para Martinez (2015) uma abordagem sustentável para questão da energia demanda soluções simultâneas entre desenvolvimento, crescimento econômico, proteção ambiental e equidade social. O imperativo da sustentabilidade no contexto da energia, na percepção de Rosen (2009), trata como uma condição exigida para que as nações alcancem em seus sistemas de energia.

O papel estratégico da energia para o desenvolvimento sustentável se manifesta no plano de ação comandado em 2015 pelas Organizações das Nações Unidas (ONU), em que originou o documento "Transformando o nosso mundo: Agenda 2030 os Objetivos do Desenvolvimento Sustentável, (ODS)”. Em linhas gerais, as questões de equidade social, políticas públicas inclusivas que assegure a elevação de direitos básicos e sustentabilidade ambiental, consta como fundamento basilar da Agenda.

Especialmente em referência ao setor energético a agenda reconhece a emergência do tema ao dispor dentre os seus dezessete objetivos, dois diretamente voltados para questão energética. O de número 7 (sete), e 13 (treze), nos quais estabelecem respectivamente metas para o setor energético em bases sustentáveis. O objetivo 7 (sete) trata de assegurar o acesso confiável, sustentável, moderno e a preço acessível à energia para todos. Consta de cinco metas, divididas em quatro temas, acesso à energia, proporção de energias renováveis, eficiência energética, cooperação internacional e infraestrutura. De modo geral, o objetivo 7, prevê que além de investimentos em infraestrutura e em tecnologias limpas, os serviços de energia, até 2030 sejam oferecidos de forma universal, moderna, confiável e a preços acessíveis.

O correspondente ao objetivo 13 (treze) se refere a adoção de medidas urgentes para o combate as mudanças 
climáticas e seus impactos. Composto de cinco metas, e oito indicadores (Ipea, 2018). A inclusão do tema energia nos ODS representa um grande passo e significa o reconhecimento do papel que a energia desempenha no desenvolvimento sustentável (Taylor et al. 2017).

Embora a temática da energia se cerce de objetivos específicos (objetivos 7 e 13), ressalta-se que a natureza integrada do tema e seus múltiplos alcances, permitem o diálogo com demais objetivos da agenda. Tratativa refutada por Gramkow (2020) ao destacar a combinação dos ODS com setor eólico, evidenciando clara sinergia entre diferentes objetivos a exemplo dos seguintes ODS: erradicação da pobreza e redução das desigualdades: (ODS 1) e (ODS 10), por contribuir para a redução das disparidades regionais e a geração de renda em regiões historicamente carentes; saúde e bem-estar (ODS 3) e energia limpa e acessível (ODS 7), por ser uma fonte de geração elétrica renovável e que não emite gases de efeito estufa (GEE) nem poluentes atmosféricos locais; indústria, inovação e infraestrutura (ODS 9), por promover a industrialização inclusiva e sustentável e fomentar a inovação; ação contra a mudança global do clima (ODS 17), por contribuir para o cumprimento dos compromissos assumidos pelo Brasil no âmbito do Acordo de Paris.

Cumpre destacar, que o caminho sugerido para alcance dos ODS se volta para necessidade e importância de implantação de políticas públicas. Os compromissos com os ODS e as políticas públicas precisam ser assumidas e implementadas nas três esferas: união, estados e municípios (Ipea, 2018). Devem se traduzir em políticas públicas "interdisciplinares, interdependentes e sistêmicas" (Sotto et al 2019, p. 62). A obtenção das metas estabelecidas pela agenda, estão sujeitas a criação de políticas públicas associada a legislação adequada de modo a afiançar o equilíbrio entre às três esferas: econômica, social e ambiental, mantendo ainda adesão com questões de interdisciplinaridade e visão sistêmica (Raeder et al. 2019).

As políticas públicas se afirmam como vínculo entre Estado e sociedade e por assim se constituir, recai sobre o primeiro a tutela de resguardar os interesses e demandas da sociedade, visando o bem coletivo. Constituem ações regulares, institucionalizadas, de governos, que tem como fins atender a sociedade (Burstynz et al. 2012). A análise voltada para setor energético é atrelada a políticas públicas assume importância determinante frente aos desafios no atual século considerando especialmente a complexidade das dinâmicas que cercam o setor. $\mathrm{O}$ processo histórico determinado entre energia e desenvolvimento ocorreu através de um formato de políticas centradas no aumento da oferta de energia (Reis, 2016).

Dester et al (2016) problematiza a questão afirmando que em virtude da ausência ou falta de eficiência das políticas públicas voltadas ao setor energético tem-se como consequência uma repercussão negativa, tanto no planejamento para ampliar a oferta de energia, como na construção da sua matriz energética. Em respostas a essas novas perspectivas, os caminhos que condicionam o setor energético mundial passam-se a exigir a adoção de políticas públicas sustentáveis como salvaguarda para alcance da sustentabilidade energética. Contemplando na sua essência tanto o uso e produção de energia de modo sustentável, como sua correlação com aspectos sociais, econômicos e ambientais, estando, portanto, regido pelos princípios do desenvolvimento sustentável (Lior, 2008; Narula et al. 2015). Bursztyn (2020) em estudo acerca dos temas: energia, desenvolvimento sustentável e políticas públicas no semiárido, defende a ideia de integração entre políticas sociais, econômicas e ambientais, em torno da questão energética.

Milhorance et al (2019) ao tratar do tema alerta para necessidade de se observar nos padrões de desenvolvimento das políticas direcionadas para expansão de parques eólicos, a necessidade de integração com outros setores. Portanto, pensar em possíveis caminhos para alcance do desenvolvimento sustentável no setor de energias renováveis se constitui um desafio. Visto que, o fornecimento de energia esteve historicamente atrelado a oferta e demanda, amparada hegemonicamente pela racionalidade técnica econômica, portanto, conflitantes com aspectos sociais, ambientais e de desenvolvimento numa perspectiva de sustentabilidade. 


\subsection{O lugar da energia no contexto do desenvolvimento}

O aumento no provimento de recursos energéticos torna-se matéria-prima para atender aos objetivos da política de desenvolvimento determinada no país na década de 1970. Nesse ambiente, sob a prerrogativa do progresso e do desenvolvimento expandiu-se a construção de grandes hidrelétricas, sustentado pela retórica de um modelo de energia limpa e renovável. Dados do Balanço Energético Nacional, ano base 2017 (Ben, 2018), atesta que a matriz energética brasileira está estruturada predominantemente por energia hidráulica respondendo por $65,2 \%$.

Contudo, as manifestações e contradições de tal modelo são percebidas e questionada mediante os impactos negativos, destacando: deslocamento de populações ribeirinhas, alagamento das áreas de florestas, processo de eutrofização das represas e seus efeitos sobre a qualidade da água e emissão de carbono (Burstynz, 2020). Como fator limitador, soma-se a estes a escassez de chuvas e riscos de apagões. A opção por esse tipo de fonte tem se revelado insustentável, no cenário mundial e especialmente no Brasil (Bermann, 2007).

A exposição do cenário de vulnerabilidades, advindos das hidrelétricas demanda ações emergenciais como investimento na diversificação da matriz energética, nesse ambiente ganha força dentre outras fontes a energia eólica. Em termos de distribuição geográfica, na região nordeste se concentra o maior potencial de expansão estando responsável por $85,4 \%$ do total de energia gerada por fonte eólica. Os primeiros lugares da região com maior capacidade de geração são liderados pelo estado do Rio Grande do Norte, Bahia e Ceará (Abeeólica, 2020). Em tese, a energia eólica se sustenta sob o argumento de energia limpa, moderna e contributiva para redução da emissão de gases de efeito estufa, acompanhada pela capacidade de geração de empregos, preservação do nível de água das barragens, desenvolvimento local nas regiões receptoras e por promover segurança operativa ao SIN (Sistema Integrado Nacional) (Pde, 2030; Simas \& Pacca, 2013; Tolmasquim, 2016; Pinto et al. 2017; Milhorance et al 2019). Além dos aspectos mencionados, Bursztyn (2020) reconhece o papel da energia eólica pela ótica da abordagem nexus, onde atende aos três eixos: segurança hídrica, energética e alimentar.

Em outra frente de debate merece atenção às discussões acerca dos impactos negativos atrelados a implantação de parques eólicos. Nesse aspecto destaca-se: afugentamento (temporário ou permanente) da fauna, supressão vegetal, soterramento de lagos temporárias, aplainamento das dunas, fragmentação florestal, impacto visual, efeitos na fauna, poluição sonora, conflitos fundiários, alteração nos campos de dunas, insegurança fundiária, impactos vinculados a práticas socialmente injustas (Meireles, 2011; Camargo-Schubert, 2017; Bezerra, 2017, et al. 2017; Empresa de Pesquisa Energética, 2020; Traldi, 2018; Gorayeb et al. 2019, Galvão et al. 2020).

O avanço de parques eólicos na percepção de Milhorance et al. (2019) possui similaridades com padrão de intervenção da construção de hidrelétricas, ou seja, ocasiona riscos pela ocupação desigual de terras, alocação assimétrica de recursos públicos, alteração sobre os meios de vida local, baixa capacidade para distribuição de eletricidade, já que o acesso não é garantido. Do exposto, contrapondo o discurso unívoco de "energia limpa" cabe destacar que para além do fator segurança energética, a energia eólica possui inter-relações com questões humanas e sociais, fato que evidencia a necessidade de uma política planejada em relação aos aspectos sociais e ambientais (Meireles et al. 2006; Meireles, 2008; 2011).

Nesse cenário torna-se considerável discutir acerca das políticas que incidem sobre tal fonte. Sua ascensão se deu a partir da criação do Programa de Incentivo às Fontes Alternativas de Energia Elétrica, 2002 (PROINFA) apontada como principal política pública destinada à expansão das fontes renováveis. As políticas de incentivos especialmente voltados para geração de energia eólica são concretizadas através de investimentos públicos, abertura de linhas de financiamentos e crédito, com forte participação do Banco Nacional de Desenvolvimento Econômico e Social (BNDES). De caráter geral, destaca-se as políticas de incentivos fiscais, leilões, tarifas feed in sistemas de ações e cotas, certificado verde, política de conteúdo local (PCL). (Camilo, 2013; Agra Neto, 2015; Aquila, 2017; Ferreira, 2017; Alves, 2019; Ipea, 2019; Pereira et al. 2019). Em nível de Brasil, destaca-se três tipos de políticas preponderantes: tecnológicas, industriais ou de criação de mercados. (Camilo, 
2013). As dinâmicas que cercam o ambiente das políticas de incentivo a fonte eólica se constituem na presença de dois atores chave, o Estado e o setor privado. O primeiro, atua como parceiro e facilitador, persuadido pela lógica do discurso do desenvolvimento. Nas palavras de Mazzucato (2014) são os governos os responsáveis diretos por implantarem políticas e mecanismos financeiros para estimular um ambiente estável no competitivo mercado das energias renováveis. Por sua vez, no setor privado as estratégias utilizadas se apresentam condizentes com a eliminação de riscos e incertezas, cuja lógica central reside em assegurar o lucro.

Por outro lado, a transição para sistemas de energia sustentável exige que os incentivos do mercado estejam alinhados aos objetivos de sustentabilidade (Fapesp, 2010). Tal propositura é endossada por Bermann (2008) ao defender a necessidade de se apoiar nas políticas públicas para que não subordinem as lógicas do mercado e mantenha seu caráter público. No contexto tratado assume especial importância a necessidade de se considerar no processo de formulação e implantação políticas públicas integradas. A opção por tal abordagem deve-se considerar os custos socioambientais para que uma política energética se desenvolva forte e sustentável (Phillipi et al. 2016).

A partir do exposto, tendo em vista a natureza complexa da temática, pensar na produção de energia para o desenvolvimento sustentável demanda uma análise multifatorial. Dentre as quais se encaixa as políticas públicas que incidem sob fonte eólica que devem estar alicerçadas pelo viés da justiça social em convergência com aspectos culturais, ambientais e territoriais, questões por vezes suprimidas mediante influências de forças políticas-econômicas dominantes.

\section{Metodologia}

Quanto aos objetivos, trata-se de uma pesquisa exploratória-descritiva, atendendo a uma abordagem qualitativa. A adoção da pesquisa exploratória justifica-se uma vez que o estudo analisa a luz da Agenda 2030 e seus respectivos objetivos quais possíveis sinergias e desafios para o setor de energia eólica no Brasil. Nesse sentido, se presta a tratar da multiplicidade e abrangência de elementos que constitui o setor de energias renováveis, precedida de uma visão pluralista trazendo a lume questões contemporâneas pouco exploradas na literatura especializada e assim fornecer subsídios para obter respostas as questões propostas pelo trabalho.

Para Gil (2008) o objetivo da pesquisa exploratória consiste na familiarização com o assunto ainda pouco conhecido ou explorado. No que concerne a pesquisa descritiva, esta consiste na exposição das características que estruturam e fundamentam o setor energético a partir de conjunturas associadas a ODS, políticas públicas e energia eólica. À modalidade de pesquisa descritiva são atribuídas particularidades como: observação, registro, analise, ordenação dos dados, frequência dos fatos ocorrem, natureza, características, causas, e relações com outros fatos sem a manipulação dos dados (Prodanov et al. 2013).

Para embasamento teórico foi realizada pesquisa bibliográfica e documental, de modo a subsidiar meios para respostas as questões levantadas no estudo. Para tanto, foi realizada pesquisa de artigos científicos em bases de dados como Scielo, ResearchGate, teses, dissertações, entre outros. A busca se deu utilizando palavras-chave: energias renováveis, fonte eólica, políticas públicas e ODS. Para pesquisa documental a consulta ocorreu em sites governamentais e foram utilizados documentos como o Plano Nacional de Energia PNE 2050, ano base 2020, o Plano Decenal de Expansão de Energia PDE (2030) ano base 2020, que tratam de diretrizes para o setor a curto, médio e longo prazo. Para embasamento sobre Agenda 2030 e ODS, utilizou-se documentos, plataformas, observatórios, relatórios das Nações Unidas Brasil, entre outros. Quanto a análise dos dados a pesquisa foi amparada na utilização do modelo de triangulação de dados, que de acordo com Vergara (2006) pode ser utilizada tanto como estratégia para a validação da pesquisa como alternativa para obtenção de novas perspectivas e conhecimentos. 


\section{Resultados e Discussão}

A fim de identificar quais possibilidades de sinergia e desafios entre Agenda 2030 e fontes renováveis, com ênfase em eólica, os 17 ODS foram sistematizados conforme os quadros (1,2 e 3) dispostos a seguir, resultando um panorama de correlação entre tais elementos. Os resultados evidenciam na sua totalidade forte associação entre os ODS e setor energético (Quadro 1).

No que se refere ao ODS1, tem-se como proposta acabar com a pobreza em todas as suas formas, em todos os lugares. Quando se estabelece sinergia com setor energético encontram-se questões relacionadas a pobreza energética encarada por Rodrigues et al (2018) como situação em que uma família não atende a condições mínimas de adequação energética e sofre um determinado grau de privação. Dentre outros fatores, o caso da pobreza energética se relaciona com a possibilidade de acesso. No caso brasileiro com o programa Luz para Todos, o país avançou na universalização do acesso, incluindo principalmente as comunidades rurais (Bursztyn, 2020). Contudo, importante ressaltar que a questão do acesso não constitui um fim em si. Outra fase da questão reside na dificuldade financeira daqueles que estão na base da pirâmide social, pois, o pagamento pelo serviço representa um gasto adicional o que constará como fator de pressão sobre o orçamento das famílias (Bursztyn, 2020). Posto isto, o desafio ao combate à pobreza energética perpassa dentre outros fatores pelo fomento a políticas sociais e econômicas que possibilite a geração de empregos e melhoria das condições financeiras para pagamento pelos serviços de energia e garantia de acesso.

Referente ao ODS 2, que trata de acabar com a fome, alcançar a segurança alimentar, melhorar a nutrição, e promover a agricultura sustentável. O objetivo recai no setor de energias renováveis como fator de sinergia enquanto a produção de energia proveniente de usinas hidrelétricas contribui com o setor de agricultura e segurança alimentar consolidando interdependências entre energia, água e alimento, portanto, se encaixando na abordagem nexus (Milhorance et al. 2019). Por outro lado, o desafio consiste na vulnerabilidade do sistema hidrelétrico, tanto pelo lado do fator climático com irregularidades de chuvas, como pelos riscos de apagões, impactos e conflitos ambientais.

Quadro 1: ODS e sinergias com setor de energias renováveis.

\begin{tabular}{|c|c|c|c|}
\hline ODS & OBJETIVO & SINERGIA & AUTOR \\
\hline 1 erRADICAR & $\begin{array}{l}\text { Acabar com a pobreza em } \\
\text { todas as suas formas, em } \\
\text { todos os lugares. }\end{array}$ & $\begin{array}{l}\text { A pobreza energética acarreta impactos negativos com } \\
\text { alcance na saúde, no desenvolvimento econômico, nas } \\
\text { oportunidades de emprego, no acesso deficiente a } \\
\text { educação e riscos ao meio ambiente. }\end{array}$ & $\begin{array}{c}\text { FGV, Caderno Opinião } \\
\text { (2017) }\end{array}$ \\
\hline 2 ERRADIC & $\begin{array}{lcc}\text { Acabar com } & \text { a fome, } \\
\text { alcançar } & \text { a } & \text { segurança } \\
\text { alimentar, } & \text { melhorar } & \text { a } \\
\text { nutrição, e promover } & \text { a } \\
\text { agricultura sustentável. }\end{array}$ & $\begin{array}{l}\text { A integração entre os setores água, energia e alimento } \\
\text { cabe o termo nexus. A água que gera energia serve ao } \\
\text { abastecimento e à produção alimentar. }\end{array}$ & $\begin{array}{c}\text { Milhorance e Bursztyn } \\
\text { (2019). }\end{array}$ \\
\hline 3 SAODEE & $\begin{array}{l}\text { Assegurar uma vida } \\
\text { saudável e promover o } \\
\text { bem-estar para todos, em } \\
\text { todas as idades. }\end{array}$ & $\begin{array}{l}\text { A maior parte das emissões antrópicas de GEEs advêm } \\
\text { de setores ligados à geração e ao consumo de energia. }\end{array}$ & Tilio Neto (2010). \\
\hline 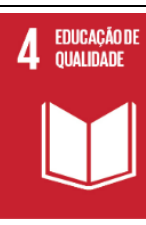 & $\begin{array}{l}\text { Assegurar a educação } \\
\text { inclusiva e equitativa de } \\
\text { qualidade, e promover } \\
\text { oportunidades r de } \\
\text { aprendizagem ao longo da } \\
\text { vida para todos. }\end{array}$ & $\begin{array}{l}\text { A infraestrutura das escolas com acesso a eletricidade } \\
\text { e internet para fins pedagógicos constitui elemento } \\
\text { contributivo para promoção de avanços no processo de } \\
\text { ensino e aprendizagem. O Censo escolar } 2017 \text { revelou } \\
\text { que as escolas brasileiras ainda possuem deficiências } \\
\text { de infraestrutura. }\end{array}$ & $\begin{array}{c}\text { Cadernos ODS } 4 \text { IPEA, } \\
\text { Instituto de Pesquisa } \\
\text { Econômica Aplicada } \\
\text { (2019). }\end{array}$ \\
\hline
\end{tabular}




\begin{tabular}{|c|c|c|c|}
\hline 5 IEUALADER & $\begin{array}{l}\text { Alcançar igualdade de } \\
\text { gênero e empoderar todas } \\
\text { as mulheres e meninas. }\end{array}$ & $\begin{array}{l}\text { A falta de acesso à energia atinge, principalmente, } \\
\text { mulheres e crianças de países em desenvolvimento, } \\
\text { que tradicionalmente são encarregadas dos serviços } \\
\text { energéticos. }\end{array}$ & $\begin{array}{l}\text { Cadernos Temáticos, } \\
\text { ONU, BR, (2018). }\end{array}$ \\
\hline 6 AgUAPOTANEL & $\begin{array}{l}\text { Garantir disponibilidade e } \\
\text { manejo sustentável da água } \\
\text { e saneamento para todos. }\end{array}$ & $\begin{array}{l}\text { A escassez hídrica afeta a disponibilidade de energia. } \\
\text { Aproximadamente } 90 \% \text { da produção global de energia } \\
\text { elétrica é intensiva no uso de água. }\end{array}$ & UNESCO (2014), \\
\hline
\end{tabular}

Fonte: Autores (2021).

O resultado obtido para o ODS 3, assegurar uma vida saudável e promover o bem-estar para todos, em todas as idades; indica sinergia com o setor na medida em que o modelo de desenvolvimento energético baseado no uso de combustíveis fósseis promovem alterações climáticas e consequente problemas de saúde com a poluição do ar (Barcellos et al. 2009). A conciliação entre energia e clima trata-se de um dos maiores desafios do século (Coppe, 2011).

Sobre o ODS 4, está atrelado a garantia da educação inclusiva e equitativa de qualidade, e na promoção de oportunidades de aprendizado ao longo da vida para todos. Neste, cabe relacionar com a questão energética por duas vias, a primeira se refere ao fator estrutural, o provimento de eletricidade nas escolas assegura melhoria nas condições de aprendizagem para todos. Na segunda via, pela oportunidade de aprendizagens recai com importância singular a educação ambiental, que na percepção de Oliveira et al. (2021) pode atuar como mecanismo para inclusão da educação climática na escola, na construção de valores éticos, políticos, sociais e ambientais e desse modo contribuir para o processo educativo que remeta a mudança de postura e tomada de decisão.

O ODS 5, sobre alcançar igualdade de gênero e empoderar todas as mulheres e meninas, a sinergia consiste no fato de que os serviços energéticos, especialmente nos países pobres, são desempenhados pelas mulheres, na coleta de madeira e esterco para cozinhar e aquecer, função que chega a consumir o tempo médio de até seis horas por dia (Iea, 2005; 2008, Autolook, 2017). Dificuldade de acesso à energia resultam no acesso limitado a serviços de saúde e educação, aumento de risco de violência, sobretudo entre às mulheres (Onu, BR, 2018)

No que compete ao ODS 6, garantia de disponibilidade e manejo sustentável da água e saneamento para todos. A relação entre água e energia se apresenta em tríades como água-abastecimento urbano-energia, água-alimento-energia, águabiomassa-energia, água-gestão territorial-energia (Dias et al. 2014). Aumento do aquecimento global, queimadas, desmatamento, urbanização desordenada, uso de combustíveis fósseis, dentre outros provoca alterações climáticas que pode ocasionar secas e estiagem comprometendo a garantia e disponibilidade dos recursos hídricos e consequente efeitos negativos nas mais diversas esferas. Para Jacobi et al. (2017, p. 9) vive-se um quadro de crescente insustentabilidade em relação à água.

O ODS 7, (Quadro 2) que se refere especificamente a questão energética, trata da garantia do acesso à energia barata, confiável, sustentável e moderna para todos. Dados do Balanço Energético (Ben 2021) atestam que a participação de renováveis na matriz energética alcançou o patamar de 48,4\%. Quanto ao acesso à energia, o Pde (2030) ano base 2020, considera que a expansão da oferta de energia deve ser feita com acesso a toda população brasileira, devendo considerar aspectos socioambientais. A agenda trata ainda sobre promover o crescimento econômico sustentado, inclusivo e sustentável, emprego pleno e produtivo, e trabalho decente para todos, ODS, 8. Tal objetivo se mostra em sinergia com o setor eólico na medida em que os dados indicam um campo promissor para geração de empregos advindos de tal fonte. Simas e Pacca (2013) defendem que a energia eólica pode contribuir para o desenvolvimento regional, ao gerar empregos locais. Tal perspectiva é certificada pelos recentes números da Agencia Internacional de Energias Renováveis (Irena, 2020) em âmbito global, 
empregos em energia eólica chegam ao patamar de 1,2 milhões, considerando projetos onshore (terra) como offshore (mar). O outro lado da mesma questão, é tratado por Braga et al (2020) para contrapor tais perspectivas. O referido utiliza do argumento de que os empregos diretos gerados na implantação dos parques, além de ser menor volume, são temporários, já que após a desmobilização das obras e início da fase operacional do empreendimento, a geração de emprego é pequena.

Sobre o ODS 9, construir infraestrutura resiliente, promover a industrialização inclusiva e sustentável, e fomentar a inovação, o ODS se mostra convergente com a fonte eólica a partir da perspectiva de que o fator inovação em fontes de energia e a sustentabilidade estão relacionadas, propiciando benefícios econômicos, sociais e ambientais (Fgv, Ebape, 2016). O ODS 10, reduzir a desigualdade entre os países e dentro deles; torna-se importante buscar compensar as desigualdades regionais em termos de demanda e oferta de energia, que podem ser agravadas pela possibilidade dos efeitos adversos das mudanças climáticas (Onu, BR, 2018).

Quadro 2: ODS e sinergias com setor de energias renováveis.

\begin{tabular}{|c|c|c|c|}
\hline ODS & OBJETIVO & SINERGIA & AUTOR \\
\hline 7 ENRERAaGssivil & $\begin{array}{l}\text { Garantir acesso à energia } \\
\text { barata, } \\
\text { sustentável e moderna para } \\
\text { todos. }\end{array}$ & $\begin{array}{l}\text { A geração de energia elétrica por fontes renováveis } \\
\text { (hidráulica, eólica, biomassa, solar e outras) alcançou } \\
80,4 \% \text { da oferta total em } 2017 \text {, com participação } \\
\text { predominante da fonte hídrica } 65,2 \% \text {. }\end{array}$ & IPEA (2019). \\
\hline $\begin{array}{l}8 \text { TRABALHODEGENTEE } \\
\text { GRESCMENTO } \\
\text { EEONOMMCO }\end{array}$ & $\begin{array}{l}\text { Promover o crescimento } \\
\text { econômico sustentado, } \\
\text { inclusivo e sustentável, } \\
\text { emprego pleno e } \\
\text { produtivo, e trabalho } \\
\text { decente para todos. } \\
\end{array}$ & $\begin{array}{l}\text { No ano de } 2019 \text { o setor de energia renovável gerou } \\
11,5 \text { milhões de empregos direta e indiretamente. }\end{array}$ & $\begin{array}{l}\text { Agência Internacional de } \\
\text { energia renovável IRENA } \\
\qquad(2020) .\end{array}$ \\
\hline $\begin{array}{l}\text { INDÚSTRIA, } \\
\text { INOVAC̆̃OEE } \\
\text { INFRAESTRUTURAS }\end{array}$ & $\begin{array}{l}\text { Construir infraestrutura } \\
\text { resiliente, promover a } \\
\text { industrialização inclusiva e } \\
\text { sustentável, e fomentar a } \\
\text { inovação. }\end{array}$ & $\begin{array}{l}\text { O plano inova energia, tem por objetivo apoiar } \\
\text { empresas brasileiras no desenvolvimento e domínio } \\
\text { tecnológico em cadeias produtivas de energias } \\
\text { renováveis. }\end{array}$ & IPEA (2016). \\
\hline 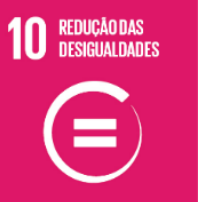 & $\begin{array}{l}\text { Reduzir a desigualdade } \\
\text { entre os países e dentro } \\
\text { deles. }\end{array}$ & $\begin{array}{l}\text { Como item de desenvolvimento é fundamental } \\
\text { universalizar o acesso à energia elétrica e a fontes } \\
\text { limpas de energia. É importante buscar compensar as } \\
\text { desigualdades regionais em termos de demanda e } \\
\text { oferta de energia. }\end{array}$ & $\begin{array}{l}\text { Cadernos Temáticos, } \\
\text { ONU, BR, (2018). }\end{array}$ \\
\hline 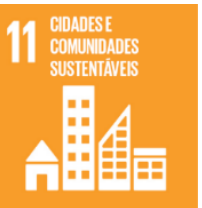 & $\begin{array}{l}\text { Tornar as cidades e os } \\
\text { assentamentos humanos } \\
\text { inclusivos, seguros, } \\
\text { resilientes e sustentáveis. }\end{array}$ & $\begin{array}{l}\text { O dilema consiste no duplo desafio: como cidades e } \\
\text { comunidades podem ser sustentáveis e, ao mesmo } \\
\text { tempo, usufruir dos recursos energéticos de forma } \\
\text { acessível, justa e renovável. }\end{array}$ & Pessoa, et al. (2019). \\
\hline
\end{tabular}

Fonte: Autores (2021).

Cidades e comunidades sustentáveis, consta como pauta do ODS 11, o tema está intrinsicamente associado a questão de energias renováveis. Conforme a ONU-Habitat (2017) um bom desenvolvimento urbano resulta em menores emissões de gases de efeito estufa, contribuindo a favor da qualidade do ar e para redução dos custos relacionados ao fornecimento de infraestrutura e serviços urbanos.

Outro tema em destaque na agenda 2030 é sobre consumo e produção responsáveis, ODS 12 (Quadro 3) O contexto a que se refere o objetivo guarda em si uma chamada para o uso eficiente dos recursos naturais. Sua sinergia com o setor de energias renováveis é clara considerando o movimento global em curso para o estabelecimento de um paradigma energético sustentável. Do lado da produção estão as perspectivas de mecanismo de desenvolvimento limpo (MDL) para redução dos 
gases de efeito estufa (GEE) bem como a eficiência energética, pois o uso eficiente de energia em sistemas de produção é peça importante para alcance do desenvolvimento sustentável (Sola et al. 2015).

Na sequência, o ODS 13, assim como o ODS 7 está voltado exclusivamente para o setor energético trata sobre tomar medidas urgentes para combater a mudança do clima e seus impactos. Nessa perspectiva, a institucionalização da Política Nacional de Mudanças do Clima (PNMC) Lei 12.187/2009 dá significância sobre a emergência do tema. Nesse processo, destacam-se os termos do Acordo de Paris, onde o Brasil oficializa o compromisso do setor de energia, alcançar uma participação estimada de 45\% de energias renováveis na composição da matriz energética em 2030 (Fgv, 2017).

Quadro 3: ODS e sinergias com setor de energias renováveis.

\begin{tabular}{|c|c|c|c|}
\hline ODS & OBJETIVO & SINERGIA & AUTOR \\
\hline $122_{\mathrm{RE}}^{\mathrm{PR}}$ & $\begin{array}{l}\text { Assegurar padrões de produção } \\
\text { e de consumo sustentáveis. }\end{array}$ & $\begin{array}{l}\text { No setor energético entre } 2005 \text { a } 20012 \text { verificou -se } \\
\text { um aumento de } 35,9 \% \text { nas emissões. Guardando } \\
\text { relação com as atividades de geração de energia, } \\
\text { produção e consumo de combustíveis. }\end{array}$ & $\begin{array}{l}\text { Documento Temático, } \\
\text { ODS, ONU, BR } \\
\text { (2018) }\end{array}$ \\
\hline & $\begin{array}{l}\text { Tomar medidas urgentes para } \\
\text { combater a mudança do clima } \\
\text { e seus impactos. }\end{array}$ & $\begin{array}{l}\text { A relação entre as mudanças climáticas e a energia } \\
\text { consta como parte do grande desafio para o } \\
\text { desenvolvimento sustentável. }\end{array}$ & $\begin{array}{l}\text { Quadrelli et al. } \\
\qquad(2007) \text {. }\end{array}$ \\
\hline & $\begin{array}{l}\text { Conservar e promover o uso } \\
\text { sustentável dos oceanos, mares } \\
\text { e recursos marinhos } \\
\text { para o desenvolvimento } \\
\text { sustentável. }\end{array}$ & $\begin{array}{l}\text { Parque eólico em ambientes marinhos (offshore) deve- } \\
\text { se considerar impactos sociais envolvendo as } \\
\text { populações costeiras que fazem uso dos recursos } \\
\text { oceânicos e marítimos próximos. }\end{array}$ & Xavier et al. (2019). \\
\hline 15 & \begin{tabular}{llr|}
\multicolumn{3}{l}{ Proteger, recuperar e promover } \\
o uso sustentável dos \\
ecossistemas & terrestres, gerir \\
de forma & sustentável as \\
florestas, & combater rà \\
desertificação, bem como deter \\
e reverter a degradação do solo \\
e a perda de biodiversidade.
\end{tabular} & $\begin{array}{l}\text { A redução do desmatamento e a restauração de } \\
\text { paisagens são consideradas ações que oferecem grande } \\
\text { potencial de mitigação das mudanças no clima. } \\
\text { terraplenagem, desmatamento, compactação do solo } \\
\text { EÓLICA). }\end{array}$ & $\begin{array}{l}\text { Documento Temático, } \\
\text { ODS, ONU, BR } \\
\text { (2018) }\end{array}$ \\
\hline $16 \begin{array}{c}\text { PAZ JUSTICAE } \\
\text { ESIIIUICOESE } \\
\text { EFGAZES }\end{array}$ & $\begin{array}{l}\text { Promover sociedades pacíficas } \\
\text { e inclusivas para o } \\
\text { desenvolvimento sustentável, } \\
\text { proporcionar o acesso à justiça } \\
\text { para todos e construir } \\
\text { instituições eficazes, } \\
\text { responsáveis e inclusivas em } \\
\text { todos os níveis. }\end{array}$ & $\begin{array}{l}\text { A Geração de energia em qualquer modalidade pode } \\
\text { ocasionar conflitos. A definição da localização de } \\
\text { parques eólicos envolve questões socioambientais que } \\
\text { podem restringir a área disponível e consequente } \\
\text { formação de conflitos mediante à forma como o } \\
\text { processo de implantação do parque eólico é } \\
\text { conduzido. }\end{array}$ & Pinto et al. (2017). \\
\hline 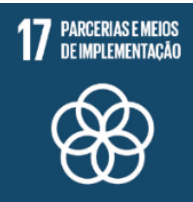 & $\begin{array}{l}\text { Fortalecer os mecanismos de } \\
\text { implementação e revitalizar a } \\
\text { parceria global para o o } \\
\text { desenvolvimento sustentável. }\end{array}$ & $\begin{array}{l}\text { O tema das mudanças climáticas assumiu relevância } \\
\text { significativa, na agenda internacional e condicionou } \\
\text { países a alianças os acordos negociações formas de } \\
\text { cooperação Protocolo de Kyoto, COP 15, acordo de } \\
\text { Paris (2015). }\end{array}$ & Leite et al. (2020). \\
\hline
\end{tabular}

Fonte: Autores (2021).

O ODS, 14, faz uma chamada para conservação e promoção do uso sustentável dos oceanos, mares e recursos marinhos para o desenvolvimento sustentável. A energia eólica offshore (mar) tem se mostrado uma opção cada vez mais viável para geração de energia renovável, sua expansão tem sido impulsionada por políticas energéticas, em resposta a preocupações ambientais, e por avanços tecnológicos (EPE, 2020). Por outra vertente, Telles (2018) chama atenção para o fato 
de que se deve considerar no processo de expansão o papel social dos territórios marinhos no Brasil. Também é citado por Xavier et al. (2019) a necessidade de garantir a prerrogativa da participação pública de modo efetivo na gênese do setor eólicomarinho brasileiro.

Quanto ao ODS 15, está proteger, recuperar e promover o uso sustentável dos ecossistemas terrestres, gerir de forma sustentável as florestas, combater à desertificação, bem como deter e reverter a degradação do solo e a perda de biodiversidade. Especialmente sobre uso sustentável dos ecossistemas terrestres que se encontra como item desafiador a expansão de parques eólicos. O Brasil, no contexto internacional, configura-se como um dos principais produtores de energia eólica (onshore). São mais de 7.000 torres em 583 parques eólicos em 12 estados brasileiros, totalizando 14,71 GW (Abeeólica, 2019). Estudos de Meireles, (2008; 2011); Meireles et al. (2006); Milhorance, (2019); Gorayeb et al. (2019), tratam dos múltiplos impactos negativos atribuídos a expansão de parques eólicos na região nordeste.

O ODS 16, guarda a intenção de promover sociedades pacíficas e inclusivas para o desenvolvimento sustentável, proporcionar o acesso à justiça para todos e construir instituições eficazes, responsáveis e inclusivas em todos os níveis. Empreendimentos energéticos em qualquer modalidade podem gerar injustiça ambiental e consequente conflitos. Sobre parques eólicos Brannstrom et al. (2017) relaciona como item potencializador de conflitos a questão da insegurança fundiária no estado do Ceará. Braga et al. (2020) identifica um campo vulnerável a conflitos considerando o aspecto social, uma vez que esses empreendimentos estão localizados, em sua grande maioria em territórios socialmente vulneráveis.

Por fim, tratando do ODS 17, que busca fortalecer os mecanismos de implementação e revitalizar a parceria global para o desenvolvimento sustentável. Nas suas entrelinhas estão guardadas palavras chaves como rompimento de barreiras fronteiriças e coalizão. Nessa direção, iniciativas globais como o Acordo de Paris e as NDC dos países bem como a Agenda 2030 e Objetivos do Desenvolvimento Sustentável (ODS) estabelecidos pela ONU merecem destaque em termos de cooperação gerada tanto na esfera interna entre governo e respectivas sociedades, quanto na esfera internacional (entre governos) em torno de objetivos comuns para a humanidade, PNE 2050 (2020).

\section{Considerações Finais}

A partir de uma abordagem multidisciplinar e integrada, tratando do contexto das energias renováveis, com ênfase na fonte eólica, buscou-se analisar a luz da Agenda 2030 e seus respectivos objetivos possíveis sinergias e desafios. Os resultados obtidos evidenciam fortes sinergias entre a Agenda 2030 e o setor de energias renováveis confirmando que a análise sobre tal contexto não pode ficar restrita a uma abordagem circunscrita apenas pela vertente da retórica de "energia limpa". Nesse sentido, sobre tal temática recai questões amplas e complexas que exige abordagens multifatoriais e sistêmicas dos fatos.

Do lado dos desafios, foram evidenciados ausência de alinhamento entre políticas públicas para o setor eólico brasileiro e ODS numa perspectiva de integração para alcance da sustentabilidade energética. As políticas de incentivo instituídas pelos governos, direcionam a fonte eólica como um modelo de desenvolvimento estritamente voltado para atender a interesses de grupos econômicos. Se refletindo na permanência do paradigma energético desvinculado da proposta de um desenvolvimento que seja sustentável.

A ocorrência de uma vasta literatura científica atestando os impactos negativos e consequente instalação de conflitos no processo de construção de parques eólicos especialmente na região nordeste evidencia a preponderância de um modelo de desenvolvimento regido sob o comando do mercado. O estabelecimento de políticas públicas integradas e inclusivas não condiz com a realidade das áreas atendidas por empreendimentos eólicos.

No que concerne a contribuição do trabalho, o estudo assume importância ao passo que pode oferecer analises importantes para o preenchimento de lacunas que visem obter respostas quanto as dinâmicas estabelecidas entre setor energético, Agenda 2030 e políticas públicas e desse modo contribuir para reorientar possíveis ajustes no paradigma de 
desenvolvimento do setor eólico no Brasil. Por outro lado, há de se considerar a necessidade de pesquisas futuras para análise mais aprofundada, que abarque demandas complexas conforme o tema exige. Nesse sentido, investigar sobre sinergias positivas e negativas acerca do fenômeno de expansão de parques eólicos na região nordeste, bem como na análise do desenho das políticas públicas que incidem na região constam como elementos contributivos para subsidiar trabalhos futuros sobre perspectivas de alcance de desenvolvimento regional e sustentável neste território.

\section{Agradecimentos}

Agradecemos a Coordenação de Aperfeiçoamento de Pessoal de Nível Superior (CAPES), a Universidade Federal de Campina Grande (UFCG) e ao Programa de Pós graduação em Engenharia e Gestão de Recursos Naturais.

\section{Referências}

Acselrad, H. \& Leroy, J. P. (1999). Novas premissas da sustentabilidade democrática. Projeto Brasil Sustentável e Democrático.

Alves, E. E. C., Steiner, A., Medeiros, M. A. \& Silva, M. E. A. (2019). From a breeze to the four winds: a panel analysis of the international diffusion of renewable energy incentive policies (2005-2015). Energy Policy, 135, 317-329.

Aquila, G., Pamplona, E. O., Queiroz, A. R., Rotela Junior, P. \& Fonseca, M. N. (2017). An overview of incentive policies for the expansion of renewable energy generation in electricity power systems and the Brazilian experience. Renewable and Sustainable Energy Reviews, $70,1090-1098$.

Agra Neto, J. (2015). Identificação das Políticas de Incentivo ao Desenvolvimento da Energia Eólica no Rio Grande do Norte (RN) (Dissertação de Mestrado em Engenharia de Produção), Universidade Federal do Rio Grande do Norte, Natal.

Associação Brasileira de Energia Eólica (ABEEÓLICA). (2019). Boletim anual de geração eólica. http://abeeolica.org.br/wpcontent/uploads/2020/06/PT_Boletim-Anual-de-Gera\%C3\%A7\%C3\%A3o-2019.pdf

Associação Brasileira de Energia Eólica (ABEEÓLICA). (2020). Boletim anual dados de 2020. http://abeeolica.org.br/wpcontent/uploads/2021/06/PT_Boletim-Anual-de-Gera\%C3\%A7\%C3\%A3o_2020.pdf

Barcellos. C., Monteiro. A. M. V., Corvalán, C., Gurgel, H. C., Carvalho, M. S., Artaxo, P., Hacon, S. \& Ragoni, V. (2009). Mudanças climáticas e ambientais e as doenças infecciosas: cenários e incertezas para o Brasil. Epidemiologia e Serviços de Saúde, 18 (3), 285-304.

Bermann, C. (2007). Impasses e controvérsias da hidreletricidade. Estudos Avançados, 21 (59), 139-153.

Bermann, C. (2008). Crise Ambiental e as Energias Renováveis. Revista Ciência e Cultura, 60 (3), 20-29.

Bezerra, M. B. C., Carvalho, D. B., Lopes, W. G. R., Sousa, T. J. S., Santos, F. C. V. \& Guzzi, A. (2017). Percepção dos impactos socioambientais decorrentes da implantação do complexo eólico Delta do Parnaíba. Gaia Scientia, 11 (1), 116 - 130.

Borges, F. Q., Baraúna, N. C. \& Chotoe, J. R. (2015). Fontes renováveis de energia elétrica e qualidade de vida em comunidades na Ilha do Marajó, Pará. Desenvolvimento Meio Ambiente, 33, 225-239.

Braga, V. M., Cypriano, J. J. C., Garce, C. A. \& Borges, E. B. P. (2020). Investimentos transformadores para o desenvolvimento sustentável: o apoio do BNDES ao setor eólico no Nordeste do Brasil. Nações Unidas: Cepal.

Brannstrom, C., Gorayeb, A., Mendes, J. S., Loureiro, C. V., Meireles, A. J. A., Silva, E. V., Freitas, A. L. R. \& Oliveira, R. F. (2017). Is Brazilian wind power development sustainable? Insights from a review of conflicts in Ceará state. Renewable and Sustainable Energy Reviews, 67, $62-71$.

Brasil. (2009). Lei $\mathrm{n}^{\circ}$ 12.187, de 29 de dezembro de 2009. Dispõe a Política Nacional sobre Mudança do Clima (PNMC). http://www.planalto.gov.br/ccivil_03/_ato2007-2010/2009/lei/112187.htm

Brasil. (2002). Lei $\mathrm{n}^{\mathrm{o}}$ 10.438, de 26 de abril de 2002. Programa de Incentivos às Fontes Alternativas de Energia (PROINFA). http://www.planalto.gov.br/ccivil_03/leis/2002/L10438.htm

Brasil. (2018). Ministério de Minas e Energia, Empresa de Pesquisa Energética. Balanço Energético Nacional (BEN) 2018. Relatório Síntese.

Brasil. (2020). Ministério de Minas e Energia, Empresa de Pesquisa Energética. Plano Decenal de Expansão de Energia 2030. MME/EPE.

Brasil. (2020). Ministério de Minas e Energia, Empresa de Pesquisa Energética. Plano Nacional de Energia 2050. Brasília: MME/EPE.

Brasil. (2020). Ministério de Minas e Energia, Empresa de Pesquisa Energética. Balanço Energético Nacional (BEN) 2021. Relatório Síntese.

Brasil. (2020). Ministério de Minas e Energia, Empresa de Pesquisa Energética. Análise socioambiental das fontes energéticas do PDE 2030. Nota Técnicas.

Bursztyn, M. A. \& Bursztyn, M. (2012). Fundamentos de Política e Gestão Ambiental: caminhos para a sustentabilidade. Garamond. 
Bursztyn, M. (2020). Energia solar e desenvolvimento sustentável no Semiárido: o desafio da integração de políticas públicas. Estudos Avançados, 34 (98), $167-186$.

Camargo-Schubert. (2017). Atlas Eólico: Paraíba. UFCG.

Camillo, E. V. (2013). As políticas de inovação da indústria de energia eólica: uma análise do caso brasileiro com base no estudo de experiências internacionais (Tese de Doutorado em Política Científica e Tecnológica), Universidade Estadual de Campinas, Campinas.

Coppe. (2011). Clima e Energia: a Coppe e os desafios da mudança climática. Universidade Federal do Rio de Janeiro.

Dias, R. S., Silva, A. C. C., Fracaro, C. \& Bley Junior, C. J. (2014). Utilização de ferramentas livres para gestão territorial do nexo água e energia. Desenvolvimento e Meio Ambiente, 30, 109-126.

Dester, M., Andrade, M. T. O. \& Bajay, S. V. (2016). Planejamento com base na matriz de energia elétrica. In: Philippi Júnior, A., Reis, L. B. Energia e Sustentabilidade. Barueri: Manole.

Fapesp. (2010). Um futuro com energia sustentável: iluminando o caminho. Rio de Janeiro: Academia Brasileira de Ciências.

Fgv Ebape. (2016). Análise do Sistema Nacional de Inovação no setor de energia na perspectiva das políticas públicas brasileiras. Edição Especial, Rio de Janeiro.

Fgv. (2017). A Geopolítica das energias renováveis: considerações iniciais. Caderno Opinião.

Gil, A. C. (2008). Como elaborar projetos de pesquisa. (4a ed.), Atlas.

Gorayeb, A. \& Brannstrom, C. (2019). Diretrizes para o planejamento socialmente justo com vistas a implantação de parques eólicos no Brasil. In: Gorayeb, A., Brannstrom, C. \& Meireles, A. J. A. Impactos socioambientais da implantação dos parques de energia eólica no Brasil. Fortaleza: Edições UFC.

Gramkow, C. (2020). Investimentos transformadores para um estilo de desenvolvimento sustentável: estudos de casos de grande impulso (Big Push) para a sustentabilidade no Brasil. Santiago: Comissão Econômica para a América Latina e o Caribe (CEPAL).

Gwec. (2019). Global Wind Report 2019. https://gwec.net/wp-content/uploads/2020/08/Annual-Wind-Report_2019_digital_final_2r.pdf

Galvão, M. L. M., Santos, M. A., Silva, N. F. \& Silva, V. P. (2020). Connections Between Wind Energy, Poverty and Social Sustainability in Brazil's Semiarid. Sustainability 2020, 12 (864), $1-25$.

Iea. International Energy Agency. (2005). Energy indicators for sustainable development: guidelines and methodologies. Vienna: International Atomic Energy Agency.

Iea. International Energy Agency. (2008). Energy indicators for sustainable development: guidelines and methodologies. Vienna: International Atomic Energy Agency

Ipea. Instituto de Pesquisa Econômica Aplicada. (2018). Agenda 2030 - ODS - Metas nacionais dos objetivos de desenvolvimento sustentável: proposta de adequação. Brasília, DF, IPEA.

Ipea. Instituto de Pesquisa Econômica Aplicada. (2019). Caderno ODS 7: Assegurar o Acesso Confiável, Sustentável, Moderno e a Preço Acessível à Energia Para Todos. Brasília, DF, IPEA.

Ipea. Instituto de Pesquisa Econômica Aplicada. (2019). Cadernos ODS 4: Assegurar a Educação Inclusiva e Equitativa e de Qualidade, e Promover Oportunidades de Aprendizagem ao Longo da Vida para Todas e Todos. Brasília, DF, IPEA.

Irena. (2020). Energia Renovável e Empregos: Revisão anual 2020. Agência Internacional de Energia Renovável, Abu Dhabi.

Jacobi, P. R. \& Grandisoli, E. (2017). Água e sustentabilidade: desafios, perspectivas e soluções. IEE-USP e Reconectta.

Leite, A. C. C., Alves, E. E. C. \& Picchi, L. (2020). A cooperação multilateral climática e a promoção da agenda da transição energética no Brasil. Desenvolvimento Meio Ambiente, 54, 379-403.

Lior, N. (2008). Energy resources and use: the present situation and possible paths to the future. Energy, 33 (6), 842-857.

Martínez, C. I. P. (2015). Energy and sustainable development in cities: a case study of Bogotá. Energy, 92 (3), $612-621$.

Meireles, A. J. A. (2008). Impactos ambientais decorrentes da ocupação de áreas reguladoras do aporte de areia: a planície Costeira da Caponga, município de Cascavel, litoral leste cearense. Confins, 2 (2), 01-23.

Meireles, A. J. A. (2011). Danos socioambientais originados pelas usinas eólicas nos campos de dunas do Nordeste brasileiro e critérios para definição de alternativas locacionais. Confins, 11 (11), 83-104.

Meireles, A. J. A, Silva, E. V. \& Thiers, P. R. L. (2006). Os campos de dunas móveis: fundamentos dinâmicos para um modelo integrado de planejamento e gestão da zona costeira. Revista Geousp, 10 (1), 101-119.

Milhorance, C. \& Bursztyn, M. (2019). Climate adaptation and policy conflicts in the Brazilian Amazon: prospects for a Nexus + approach. Climatic Change, $155,215-236$.

Mazzucato, M. (2014). O estado empreendedor: desmascarando o mito do setor público vs. setor privado. Portfolio Penguin. 
Narula, K. \& Reddy, B. S. (2015). Three blind men and an elephant: the case of energy indices to measure energy security and energy sustainability. Energy, $80,148-158$.

Oliveira, N. C. R., Oliveira, F. C. S. \& Carvalho, D. B. (2021). Educação Ambiental e mudanças climáticas: percepção e práticas dos professores em escolas sustentáveis. SciELO Preprints.

Organização das Nações Unidas, ONU. Nova Agenda Urbana. Habitat. 2017.

Pessoa, Z. S., Macedo, L. D., Seixas, S. R.C., Sales, R. M. M. S., \& Gorayeb, A. (2019). Acesso à energia e cidades sustentáveis: da Agenda 2030 às políticas na área da Ciência, Tecnologia e Inovação (CT\&I). Parcerias Estratégicas, 24 (49), 31-48.

Philippi Jr., A. \& Reis, L. B. (2016). Energia e sustentabilidade. Manole.

Pinto, L. I. C., Martins, F. R. \& Pereira, E. B. (2017). O mercado brasileiro da energia eólica, impactos sociais e ambientais. Revista Ambiente e Água, 12 (6), $1083-1100$

Prodanov, C. C. \& Freitas, E. C. (2013). Metodologia do trabalho científico: métodos e técnicas da pesquisa e do trabalho acadêmico. Novo Hamburgo: Feevale.

Programa das Nações Unidas para o desenvolvimento. PNUD. (2015). Acompanhando a Agenda 2030 para o desenvolvimento sustentável: subsídios iniciais do Sistema das Nações Unidas no Brasil sobre a identificação de indicadores nacionais referentes aos Objetivos de Desenvolvimento Sustentável. Brasília: PNUD.

Programa das Nações Unidas para o desenvolvimento. PNUD. (2018) Documentos temáticos: Objetivos de Desenvolvimento Sustentável - 6 - 7 - 11 - 12 - 15. Brasília.

Pereira, S. R. N. \& Fonseca, A. A. M. (2019). Energia Eólica e desenvolvimento no semiárido baiano. Papeles de Coyuntura, 46, 92-120.

Quadrelli, R. \& Peterson, S. (2007). The energy-climate challenge: Recent trends in CO2 emissions from fuel combustion. Energy Policy, 35 (11), $5938-5952$.

Raeder. S. T. O. \& Menezes P. M. (2019). A relação entre interdisciplinaridade e a implementação da Agenda 2030. Parcerias Estratégicas, 24 (49), $09-28$.

Reis, L. B. (2016). Energia, ambiente, sociedade e sustentabilidade. In: PHILIPPI JR., A., REIS, L. B. Energia e sustentabilidade.

Rodrigues, T. P. \& Gonçalves, S. (2018). Pobreza energética: evidências para famílias da área rural do Brasil. In: Anais do Congresso da Sociedade Brasileira de Economia, Administração e Sociologia Rural, Campinas, SP.

Rosen, M. A. (2009). Energy sustainability: a pragmatic approach and illustrations. Sustainability, 1, (1), 55-80.

Simas, M. \& Pacca, S. (2013). Energia eólica, geração de empregos e desenvolvimento sustentável. Estudos Avançados, 27 (77), 99-115.

Sola, A. V. H., Mota, C. M. M. (2015). Melhoria da eficiência energética em sistemas motrizes industriais. Production, 25 (3), 498-509.

Sotto, D., Ribeiro, D. G., Abiko, A. K., Sampaio, C. A. C., Navas, C. A., Marins, K. R. C., Sobral, M. C. M., Philippi Jr, A. \& Buckeridge, M. S. (2019). Sustentabilidade urbana: dimensões conceituais e instrumentos legais de implementação. Estudos Avançados, 33 (97), 61-80.

Taylor, P. G., Abdalla, K., Quadrelli, R. \& Vera, I. (2017). Better energy indicators for sustainable development. Nature Energy, n. 2 (8), 17117.

Telles. D. H. Q. (2018). Abordagem territorial para a Geografia Marinha: reflexões a partir do planejamento espacial e a gestão integrada. Desenvolvimento e Meio Ambiente, 49, 336-354.

Tilio Neto, P. (2010). Ecopolítica das mudanças climáticas: o IPCC e o ecologismo dos pobres. Rio de Janeiro: Centro Edelstein de Pesquisas Sociais.

Tolmasquim, M. T. (2016). Energia renovável: hidráulica, biomassa, eólica, solar, oceânica. Rio de Janeiro: Empresa de Pesquisa Energética.

Traldi, M. (2018). Os impactos sócioeconômicos e territoriais resultantes da implantação e operação de parques eólicos no semiárido brasileiro. Revista Electrónica de Geografía y Ciencias Sociales Universitat de Barcelona, 22 (589), 1 - 34.

Unesco. (2014). United Nations World Water Assessment Programme. The United Nations World Water Development Report. Paris: UNESCO.

Vergara, S. C. (2006). Métodos de pesquisa em administração. Atlas.

World Energy Outlook. (2017). OECD/IEA. International Energy Agency. https://www.oecd.org/about/publishing/Corrigendum_EnergyOutlook2017.pdf

Xavier, T., Gorayeb, A. \& Brannstrom, C. (2019). Parques eólicos offshore no Brasil e os potenciais impactos sociais: aplicação de matrizes SWOT. In: Gorayeb, A., Brannstrom, C. \& Meireles, A. J. A. Impactos socioambientais da implantação dos parques de energia eólica no Brasil. Fortaleza: Edições UFC. 